\title{
Organization design challenges: results from a practitioner survey
}

\author{
Nicolay Worren ${ }^{1 *}$ (D) Jeroen van Bree ${ }^{2}$ and William Zybach ${ }^{3}$
}

\author{
* Correspondence: \\ nicolay.worren@nmbu.no \\ ${ }^{1}$ School of Economics and Business, \\ Norwegian University of Life \\ Sciences (NMBU), P.O. Box 5003, \\ 1432 Aas, Norway \\ Full list of author information is \\ available at the end of the article
}

\begin{abstract}
We conducted a survey to identify the most important challenges faced by consultants who support managers in re-designing their organizations. The results indicate that the most frequently encountered challenges are (1) creating realistic estimates regarding the time and resources required to complete the project, (2) understanding patterns of collaboration or information exchange across units in the organization, (3) handling political aspects of the re-design process and helping participants "see the bigger picture" (as opposed to "protecting their own turf"), and (4) evaluating whether the new organizational model has had the intended effects. We discuss the implications of the study for both practitioners and scholars.
\end{abstract}

\section{Introduction}

Many practitioners make a distinction between "content" and "process" issues with regard to organization design. By "content," they typically refer to knowledge, tools, and principles related to the organizational models that are developed and implemented. By "process," they refer to knowledge, tools, and principles related to the process that one follows during a re-organization or other major organizational change.

It is clear that practitioners view process issues as critical in order to succeed in a redesign initiative. At several practitioner conferences that we attended, more time was spent on discussing how to manage a re-design effort than on the actual organizational model that was developed. Another indication is that the consulting firms that we have worked in (or with) have all had process frameworks or methodologies (as described in Werr et al. 1997). Most of these frameworks do not contain prescriptions regarding content (e.g., which organizational model to select in which circumstances) but focus on process: They divide the organization design process into steps or phases and may also contain recommended tools for each major step.

This situation is not reflected in academic research. The majority of journal articles that are published are theory-driven rather than practice oriented, even though organization design is usually considered an applied field. This includes the current journal: Few of the articles published in the Journal of Organization Design are concerned about the design process (Snow 2018).

Nonetheless, several books-including some written by scholars-do offer prescriptions for how one should plan and manage the organization design process (e.g., Burton et al. 2015; Nadler and Tushman 1997; Stanford 2015; Worren 2018). We have 
used these books in our work and believe that they provide sensible advice to practitioners. However, they seem to be based on the author's personal observations or consulting experience. There is little or no systematic knowledge about how practitioners view the design process, and more importantly, what they consider to be the main challenges in planning and managing organizational re-design processes. Such knowledge would seem to be important for at least two reasons. It might help practitioners (e.g., consultants) improve training courses and develop new tools and frameworks to support the design process. Secondly, it might help scholars in identifying research projects that might produce findings that help improve the way organization design is performed.

The purpose of our project was thus to better understand the challenges facing practitioners. We conducted a survey among 176 consultants who are engaged in organization design projects. The survey contained 25 items and was divided into four parts, corresponding to phases covered in most organization design methodologies ${ }^{1}$. The first is "Scoping the engagement and preparing the project." In this phase, one establishes the project and creates a plan for the work together with the client. The second phase is "Analyzing the current organization." The purpose of this phase is to gain an understanding of how the organization works today and the key opportunities and challenges. The third phase is "Developing the new design." In this phase, one typically identifies a set of design criteria and creates one or more alternative options (i.e., new organizational models or adjustments to the current model). One also evaluates the proposal(s) and makes a decision about implementing the proposed model (or a revised version of it). In the final phase, "Implementing the new organizational model," employees are allocated to roles according to the new model, and other changes may also be implemented to support the new model.

In the following, we report on the key findings for each part of the survey. The questionnaire included an open text field; we include some represenentative quotes (see the Appendix for further details about the methodology).

\section{Key findings}

\section{Part 1: Scoping the engagement and preparing the project}

The items in this part addressed key activities that are undertaken at the beginning of a project in order to establish the project team, agree on the scope of the project with the client, and create a plan for the work. In the practitioner literature, this step is sometimes called "contracting," referring to the need for a social contract or agreement between consultant and client about how they are going to work together (Block 2011).

\section{Results}

Only around three out of 10 respondents indicated that it is often or always a challenge to create a common understanding with the client or decision maker with regards to the project mandate, or identify who the real stakeholders for the project are (see Table 1). In contrast, nearly six out of 10 respondents stated that it is often or always a challenge to create realistic estimates regarding the time and resources required to

${ }^{1}$ Different consulting methodologies use slightly different ways of dividing up the re-design process. For example, in Worren (2018), a methodology is described that is divided into three phases (planning, design, and implementation). 
Table 1 Items in the survey divided by section, with some descriptive data (the scale used was 15)

\begin{tabular}{|c|c|c|c|c|c|}
\hline Part/design phase & No. & Item & Average & Std. Dev. & $\begin{array}{l}\text { Often or always } \\
\text { a challenge: }\end{array}$ \\
\hline \multirow[t]{5}{*}{$\begin{array}{l}\text { Scoping the } \\
\text { engagement and } \\
\text { preparing the } \\
\text { project }\end{array}$} & 1 & $\begin{array}{l}\text { Creating realistic } \\
\text { estimates regarding the } \\
\text { time and resources } \\
\text { required to complete the } \\
\text { project }\end{array}$ & 3.6 & 1.0 & $58 \%$ \\
\hline & 2 & $\begin{array}{l}\text { Ensuring that the project } \\
\text { team is composed of } \\
\text { people with relevant and } \\
\text { complementary skills and } \\
\text { experience }\end{array}$ & 3.1 & 1.1 & $39 \%$ \\
\hline & 3 & $\begin{array}{l}\text { Finding relevant cases } \\
\text { from other comparable } \\
\text { organizations that we } \\
\text { could learn from }\end{array}$ & 3.5 & 1.2 & $54 \%$ \\
\hline & 4 & $\begin{array}{l}\text { Creating a common } \\
\text { understanding with the } \\
\text { client /decision maker } \\
\text { regarding the project } \\
\text { mandate }\end{array}$ & 3.0 & 1.1 & $33 \%$ \\
\hline & 5 & $\begin{array}{l}\text { Identifying who the real } \\
\text { stakeholders for the } \\
\text { project are }\end{array}$ & 2.7 & 1.1 & $24 \%$ \\
\hline \multirow[t]{6}{*}{$\begin{array}{l}\text { Analyzing the } \\
\text { current } \\
\text { organization }\end{array}$} & 6 & $\begin{array}{l}\text { Understanding the } \\
\text { implications of the } \\
\text { organization's strategy for } \\
\text { the organization }\end{array}$ & 2.9 & 1.1 & $33 \%$ \\
\hline & 7 & $\begin{array}{l}\text { Identifying the strengths } \\
\text { and weaknesses of the } \\
\text { current organization }\end{array}$ & 2.5 & 1.0 & $18 \%$ \\
\hline & 8 & $\begin{array}{l}\text { Identifying the mandates } \\
\text { or goals pursued by the } \\
\text { different sub-units in the } \\
\text { organization }\end{array}$ & 3.0 & 1.1 & $37 \%$ \\
\hline & 9 & $\begin{array}{l}\text { Understanding the formal } \\
\text { governance processes } \\
\text { and reporting } \\
\text { relationships in the } \\
\text { current organization }\end{array}$ & 2.7 & 1.0 & $21 \%$ \\
\hline & 10 & $\begin{array}{l}\text { Understanding how } \\
\text { people collaborate and/or } \\
\text { exchange information } \\
\text { across units in the } \\
\text { current organization }\end{array}$ & 3.4 & 1.0 & $55 \%$ \\
\hline & 11 & $\begin{array}{l}\text { Documenting how the } \\
\text { organization utilizes its } \\
\text { resources (e.g., in } \\
\text { different units, work } \\
\text { processes, locations) }\end{array}$ & 3.3 & 1.0 & $47 \%$ \\
\hline \multirow[t]{2}{*}{$\begin{array}{l}\text { Developing the } \\
\text { new design }\end{array}$} & 12 & $\begin{array}{l}\text { Gaining consensus } \\
\text { among stakeholders for a } \\
\text { set of design criteria (or } \\
\text { priorities/principles for } \\
\text { the new model) }\end{array}$ & 3.2 & 1.2 & $42 \%$ \\
\hline & 13 & $\begin{array}{l}\text { Ensuring that the client } \\
\text { or decision maker does } \\
\text { not make a premature }\end{array}$ & 3.5 & 1.1 & $59 \%$ \\
\hline
\end{tabular}


Table 1 Items in the survey divided by section, with some descriptive data (the scale used was 15) (Continued)

\begin{tabular}{|c|c|c|c|c|c|}
\hline Part/design phase & No. & Item & Average & Std. Dev. & $\begin{array}{c}\text { Often or always } \\
\text { a challenge: }\end{array}$ \\
\hline & & $\begin{array}{l}\text { commitment to a } \\
\text { preferred model before } \\
\text { exploring alternative } \\
\text { options }\end{array}$ & & & \\
\hline & 14 & $\begin{array}{l}\text { Identifying the } \\
\text { consequences of the } \\
\text { tentative or proposed } \\
\text { organizational models } \\
\text { (e.g., consequences with } \\
\text { regards to coordination, } \\
\text { resource utilization, costs, } \\
\text { productivity, employee } \\
\text { morale) }\end{array}$ & 3.3 & 1.1 & $47 \%$ \\
\hline & 15 & $\begin{array}{l}\text { Ensuring that the client } \\
\text { and key stakeholders feel } \\
\text { a sense of ownership } \\
\text { toward the selected } \\
\text { model }\end{array}$ & 3.1 & 1.1 & $39 \%$ \\
\hline & 16 & $\begin{array}{l}\text { Ensuring that managers } \\
\text { and employees (people } \\
\text { outside the design team) } \\
\text { understand the rationale } \\
\text { behind the decision } \\
\text { alternatives (i.e., } \\
\text { organizational models) }\end{array}$ & 3.5 & 1.0 & $55 \%$ \\
\hline & 17 & $\begin{array}{l}\text { Incorporating suggestions } \\
\text { and concerns from } \\
\text { stakeholders when } \\
\text { revising the tentative/ } \\
\text { proposed model(s) }\end{array}$ & 2.7 & 1.0 & $23 \%$ \\
\hline & 18 & $\begin{array}{l}\text { Helping participants in } \\
\text { the process see the larger } \\
\text { picture, as opposed to } \\
\text { "protecting their own } \\
\text { turf" }\end{array}$ & 3.7 & 1.1 & $62 \%$ \\
\hline & 19 & $\begin{array}{l}\text { Ensuring that the } \\
\text { decision maker(s) reach a } \\
\text { decision regarding the } \\
\text { preferred new } \\
\text { organizational model }\end{array}$ & 3.2 & 1.1 & $42 \%$ \\
\hline & 20 & $\begin{array}{l}\text { Ensuring that the } \\
\text { organizational model that } \\
\text { is selected meets the } \\
\text { design criteria (or } \\
\text { priorities/principles) } \\
\text { established earlier in the } \\
\text { process }\end{array}$ & 2.8 & 1.1 & $27 \%$ \\
\hline \multirow[t]{2}{*}{$\begin{array}{l}\text { Implementing the } \\
\text { new organizational } \\
\text { model }\end{array}$} & 21 & $\begin{array}{l}\text { Operationalizing the } \\
\text { selected organizational } \\
\text { model (e.g., identifying } \\
\text { new roles, defining } \\
\text { sub-units and interfaces, } \\
\text { formulating key } \\
\text { performance indicators } \\
\text { (KPIs), etc.) }\end{array}$ & 3.3 & 1.1 & $49 \%$ \\
\hline & 22 & $\begin{array}{l}\text { Staffing the new } \\
\text { organization (i.e., }\end{array}$ & 3.2 & 1.0 & $41 \%$ \\
\hline
\end{tabular}


Table 1 Items in the survey divided by section, with some descriptive data (the scale used was 15) (Continued)

\begin{tabular}{|c|c|c|c|c|c|}
\hline Part/design phase & No. & Item & Average & Std. Dev. & $\begin{array}{c}\text { Often or always } \\
\text { a challenge: }\end{array}$ \\
\hline & & $\begin{array}{l}\text { allocating people to new } \\
\text { roles, or having people } \\
\text { apply for available roles) }\end{array}$ & & & \\
\hline & 23 & $\begin{array}{l}\text { Adapting the } \\
\text { infrastructure (e.g., IT } \\
\text { systems, buildings, offices) } \\
\text { to the new organizational } \\
\text { model }\end{array}$ & 3.5 & 1.1 & $52 \%$ \\
\hline & 24 & $\begin{array}{l}\text { Conducting other } \\
\text { interventions aimed at } \\
\text { achieving changes in } \\
\text { knowledge, attitudes, or } \\
\text { behaviors to support the } \\
\text { new organizational model }\end{array}$ & 3.5 & 1.0 & $55 \%$ \\
\hline & 25 & $\begin{array}{l}\text { Evaluating whether the } \\
\text { new organizational model } \\
\text { achieves the intended } \\
\text { effect }\end{array}$ & 3.8 & 1.0 & $65 \%$ \\
\hline
\end{tabular}

complete a project (Fig. 1). The second most challenging task is to find relevant cases from other comparable organizations; five out of 10 respondents indicated that it was often or always a challenge (Fig. 2).

\section{Interpretation}

This result reflects the fact that organization design projects are complex and unpredictable: One may not have a full overview of the activities that need to be undertaken to make the project succeed when the project commences. For this reason, it is difficult to create reliable estimates with regards to time and resources. As one respondent remarked:

[...] most projects are never just organization design. They touch at the heart of strategy, at the intersection of process, technology and people and quickly elevate the urgency / sensitivity to changes and bring to light personal wins and losses.

However, there are also other factors that may have influenced this rating. The average manager only participates in a handful of major re-designs during his or her career

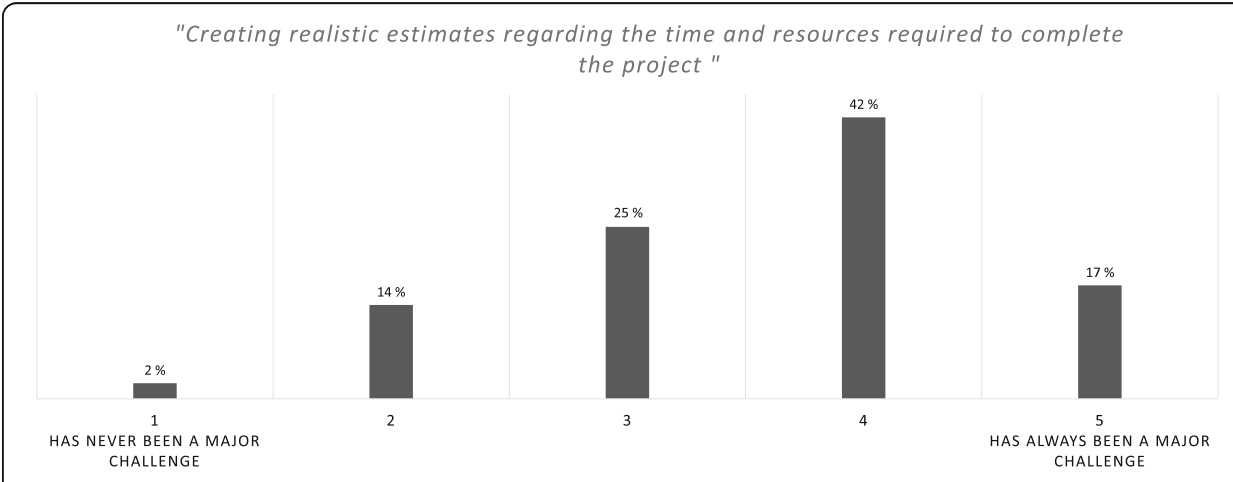

Fig. 1 Results for item 1 in the survey 


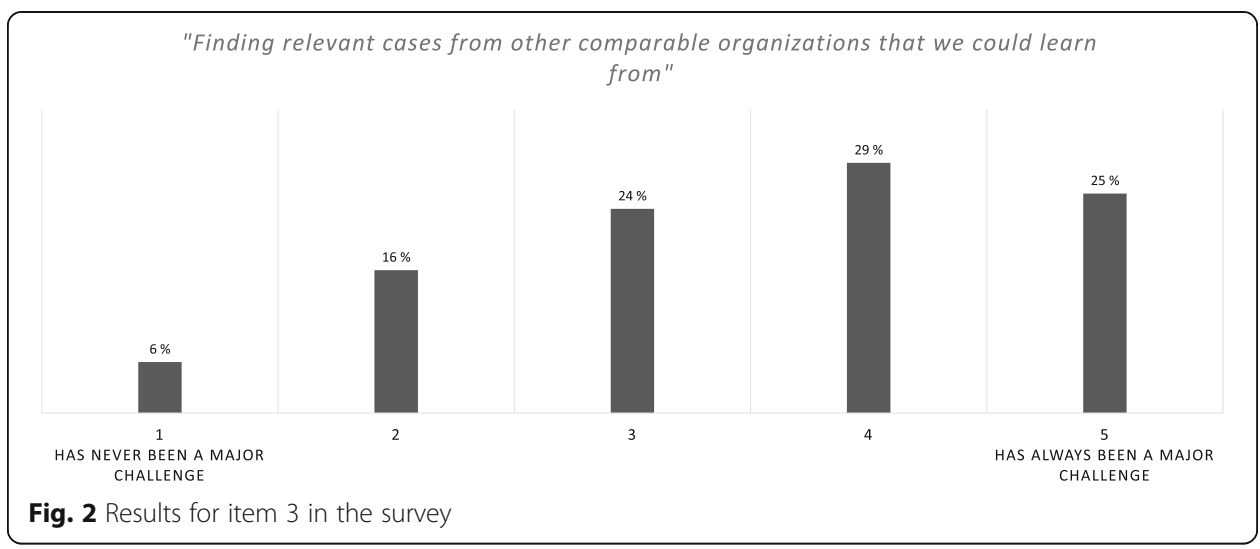

and may underestimate the level of effort that is required. This is reflected in the following two quotes:

Most clients want it done fast and do not recognize how much time it will take to solicit input from organizational members. They (...) downplay the importance of broader participation

This contracting step is of course dependent on the quality and accuracy of the knowledge in the system

The results partly reflect the experience level of the practitioner him/herself. We found that there was a negative correlation $(r=-.18, p=<0.05)$ between the number of projects completed and the rating of this particular challenge. In other words, more experienced practitioners are somewhat less likely to rate this as a frequent challenge on their projects compared to less experienced practitioners. We would speculate that more experienced consultants not only have better skills with regards to scoping a project, but that they also have more leverage to convince the client to invest sufficient time and money in the project.

There may also be several explanations for the difficulty of finding relevant cases from comparable organizations. Worren (2018) argued that there is a lack of systematic methods for capturing key organization design variables; organizational designs are often documented in an idiosyncratic manner. Secondly, because of confidentiality concerns, detailed information about previous projects may not be made available to other teams within the consulting firm. However, even if one gains access to documents from prior projects and even if one improves how information is documented, there will always be some information (e.g., about the context, about the process used in a previous project) that is not fully captured in formal documents. Consultants may need to go and talk directly to those who participated in a prior project to understand what they did.

\section{Part 2: Analyzing the current organization}

The items in this part covered activities aimed at understanding and documenting the current organization, often referred to as the "As is" phase among consultants. 
Typically, this is done by reviewing company documents, interviewing representatives from different units, or conducting workshops. In some cases, one may also collect financial information and/or distribute surveys to managers, for example, in order to compare resource utilization in different units.

\section{Results}

We see quite some variation among the items (see Table 1). Only around two out of 10 respondents indicated that it is often or always a challenge to identify the strengths and weaknesses of the current organization or to understand the formal governance processes and reporting relationships. In contrast, more than five out 10 indicated that it is often or always a challenge to understand how people collaborate and/or exchange information across units in the organization. A high number of respondents (nearly five out of 10) also indicated that it was challenging to document how the organization utilizes its resources in different units, work processes, and locations (Figs. 3 and 4).

\section{Interpretation}

Some information is readily available to consultants and even formalized (e.g., organization charts showing the existing reporting lines). However, other types of information (e.g., informal relations, work process interdependencies, and resource utilization) are not readily available, even though they may be more important in order to support effective decisions.

The key constraint that consultants often face is that data collection is timeconsuming and therefore costly. Clients may want to reduce the cost and proceed directly to the design phase. As three respondents noted:

Lack of as-is data is always a major challenge resulting in an expensive analysis and documentation phase which clients don't want to spend money on

An absence of process maps/definitions is often a challenge - there is no record of what people actually do, sometimes not even job descriptions

My answer regarding the utilization of resources is rooted in the difficulty in gathering accurate data to perform this task, especially in a large, global organization

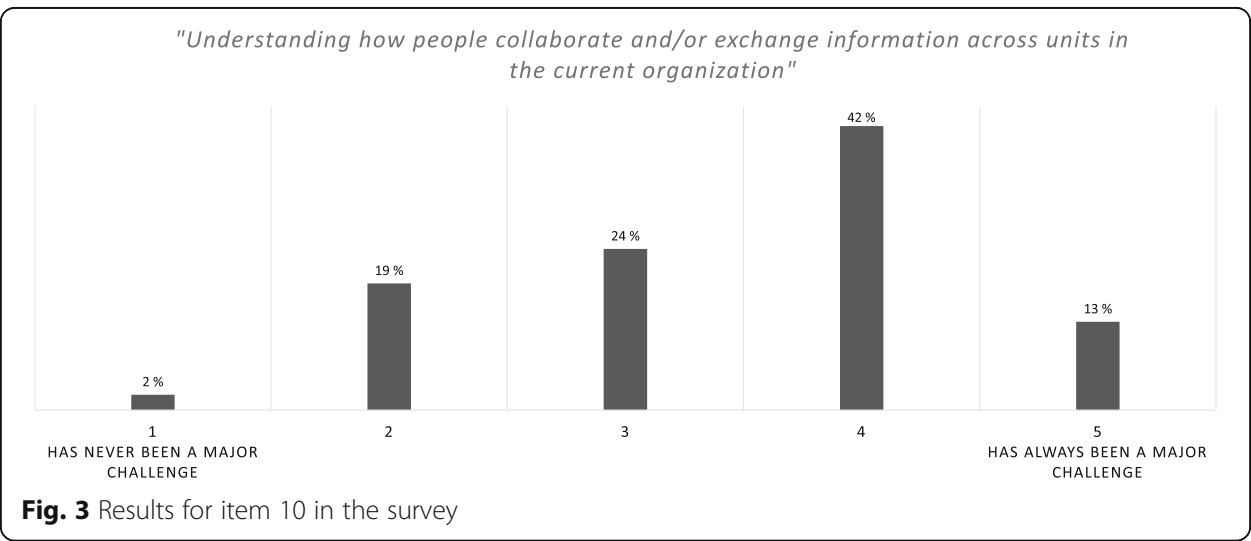




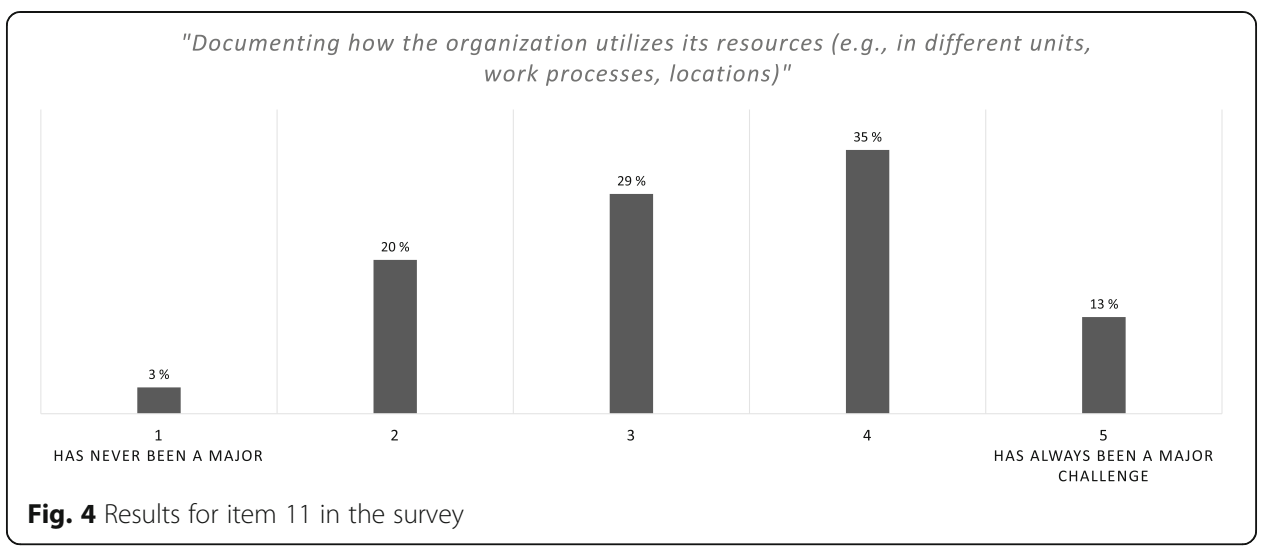

Obtaining valid data about the current organization is not only a question of time and cost, however, but also requires a willingness to examine current practices and share information with the consultants. As one respondent noted:

These challenges are present due to the unwillingness of the institutions I work with to truly acknowledge or disclose the truths.

\section{Part 3: Developing the new design}

The nine items in this part of the survey concern the core design activities related to the development, evaluation, and selection of a new organizational model. This phase may have a duration of several weeks or even months, depending on the scope of the proposed change, the complexity of the organization and the degree of divergence in stakeholder interests and preferences. But the purpose is typically to achieve consensus for a set of goals (or design criteria) and identify a new organizational model-possibly in combination with other measures-that will help address the goals or criteria.

\section{Results}

According to the respondents, the least challenging aspect is to incorporate suggestions and concerns when revising a tentative or proposed model; only around two out of 10 indicated that this is often or always a challenge (Table 1). In contrast, more than six out of 10 indicated that it is often or always a challenge to help participants see the larger picture, as opposed to "protecting their own turf" (Fig. 5). Similarly, nearly six out of 10 indicated that it is often or always a challenge to ensure that the client or decision maker does not make a premature commitment to a preferred model before exploring alternative options (Fig. 6). Finally, more than five out of 10 indicated that it is often or always a challenge to ensure that managers and employees (people outside the design team) understand the rationale behind the decision alternatives (i.e., organizational models) (Fig. 7).

\section{Interpretation}

The tendency to "protect one's own turf" reminds us that organizational re-design isor may deteriorate into-a political process. One consequence is that participants may 


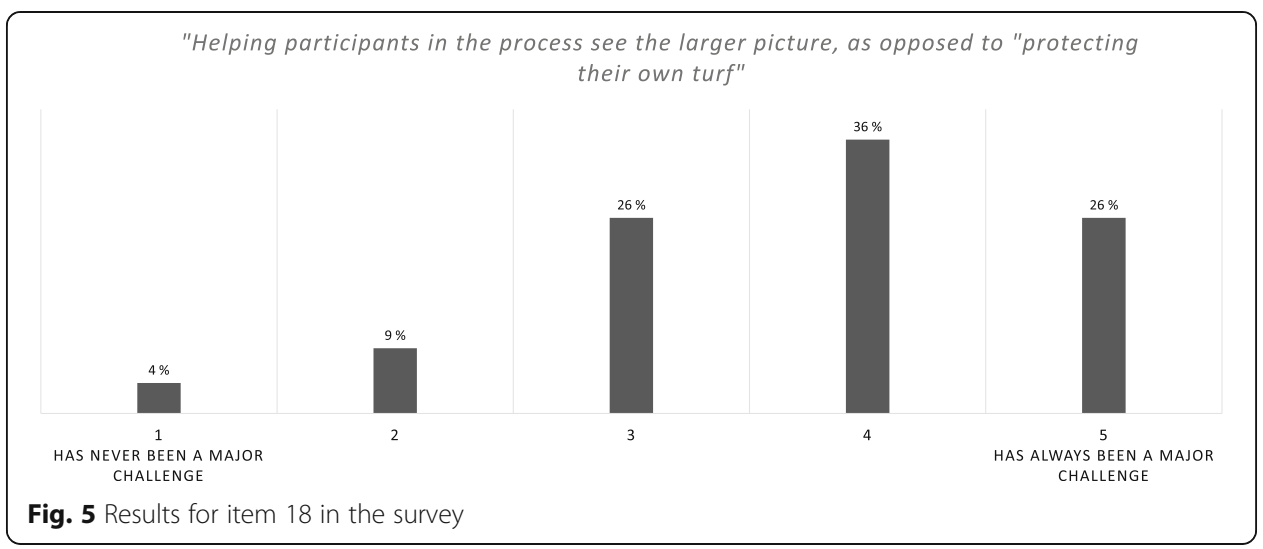

spend more time and energy on protecting their own status or their unit's current position, rather than considering viable options from the organization's point of view. As one respondent remarked:

It is at this stage that territorial protection and internal politics start to come into play. People tend to think in terms of losses rather than gains

The comments also suggest that there may be emotional factors, combined with cognitive biases, that influence how participants reason and act during the re-design process. As in other types of organizational change, one may observe that participants suffer from "loss aversion" and have trouble envisioning an alternative reality:

The biggest issue is a misunderstanding of what design criteria are and what good criteria look like. Clients are often too wedded to "what is" rather than "what could/should be"

This is clearly an impediment to the design process. Paul Tolchinsky, a wellrespected practitioner in the field, put it in the following way: "You cannot design what you cannot imagine" (personal communication, November 2, 2011).

As for other types of strategic decisions, one will generally achieve better results by carefully considering multiple options before making a choice with regard to the new

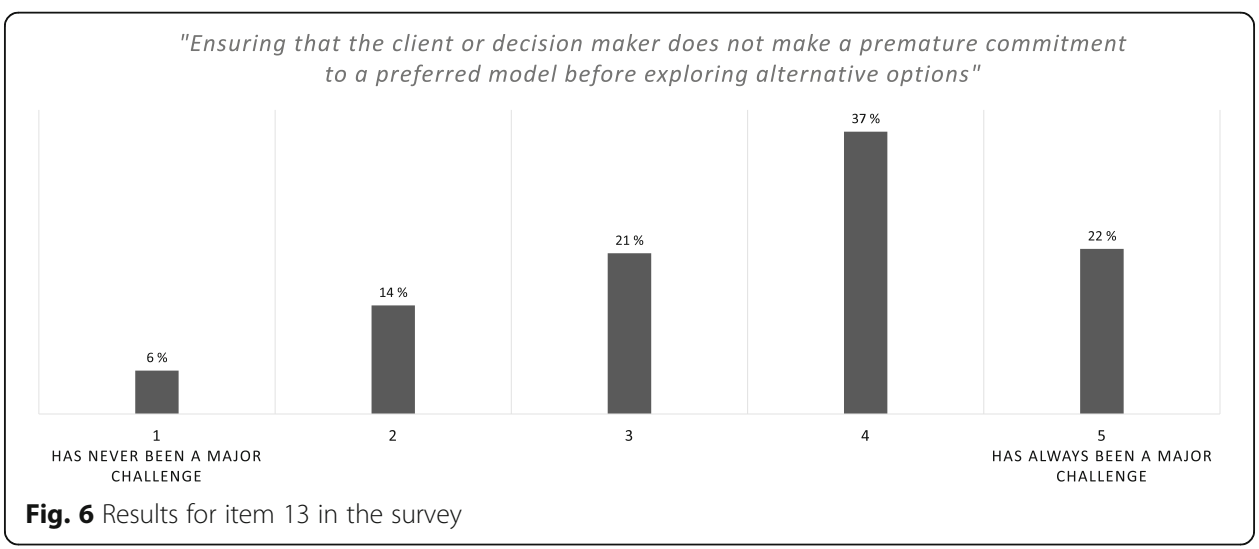




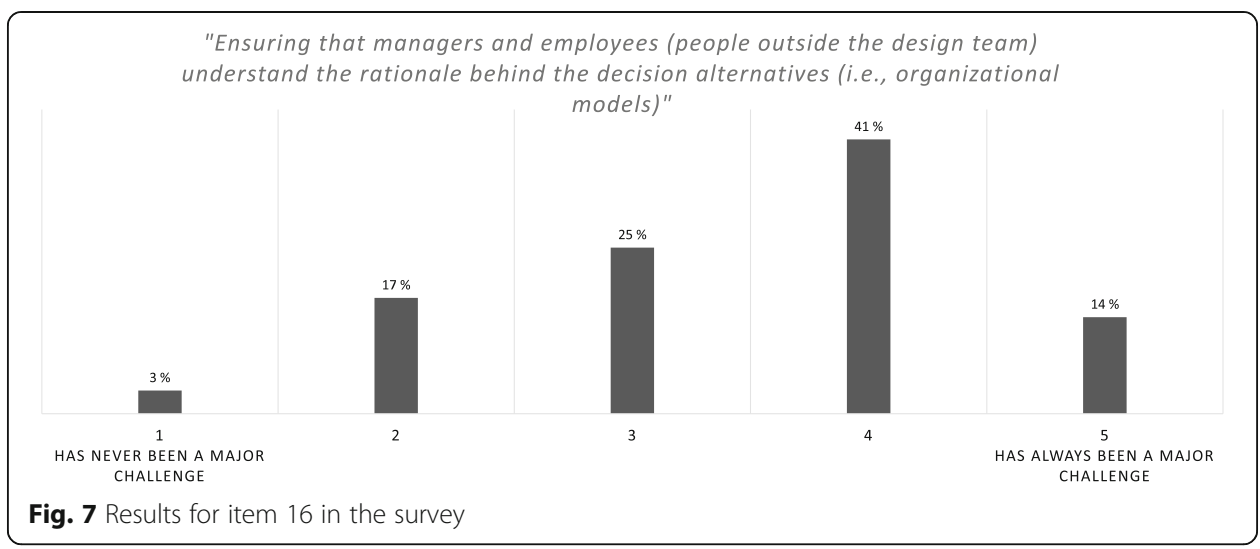

organizational model (Basu and Savani 2017; Nutt 2002). However, the tendency noted by the respondents is to proceed rather quickly in this phase:

Often times leaders do not want to give the time to exploring conceptual options... they want to get on with it, there are budget pressures to get it done

The difficulty of creating understanding and acceptance among employees for the design choices probably reflect the fact that new organizational models are often developed by project teams. Even though a large number of people may potentially be asked to provide input to the project (e.g., by participating in interviews or workshops), it does not necessarily follow that they all will understand the rationale behind the model that is finally chosen.

The development of explicit design criteria is often recommended as a key step in creating a systematic and transparent decision process, and one that maximizes the chance of selecting a model that addresses the key challenges facing the organization. All of the stakeholders may potentially participate in the identification of design criteria, which are subsequently the basis for evaluating alternative options (and potentially also for communicating the rationale behind the decision). The respondents evaluated this task as moderately challenging (more than 4 out of 10 indicated that it was often or always a challenge). At the same time, it seems like it requires particular skills to manage this aspect of the process. In the words of one respondent:

Identification of design criteria seems simple to stakeholders because they don't have a concept of the new organization and associated trade-offs yet. When design options are presented, stakeholders begin to understand implications of criteria. Typically, they will attempt to redo criteria in order to meet an expected design outcome. Practitioners require courage and candor to help stakeholders understand how tweaks in the design will compromise the original design criteria (intent)

\section{Part 4: Implementing the new organizational model}

The items in this section covered activities that are undertaken in order to implement the selected organizational model. A new organization chart is typically published on the firm's intranet. Implementing the new model depicted on the chart usually involves 
the establishment of new organizational units and assigning people to the roles in these units. However, as one has usually only discussed the overall model in the design phase, one first needs to operationalize the selected model (e.g., to define new roles, sub-units, and interfaces) before the model can be implemented. In addition, several other changes (e.g., related to governance, metrics, processes, behaviors) may need to be implemented in order to underpin the new organizational model and fulfill the design criteria.

\section{Results}

The five items in this section were all viewed as moderately to highly challenging (Table 1). The issue that was considered the most challenging is related to evaluation: More than six out of 10 respondents indicated that it is often or always a challenge to evaluate whether the organization has achieved the intended effect (Fig. 8).

More than five out of 10 respondents also indicated that it is often or always a challenge to conduct other interventions aimed at changes in knowledge, attitudes, or behaviors to support the new organizational model (Fig. 9).

In comparison, the remaining three items in this section-related to operationalization $(\mathrm{Q} 21)$, staffing of new roles $(\mathrm{Q} 22)$, and infrastructure $(\mathrm{Q} 23)$ - were evaluated as moderately challenging.

\section{Interpretation}

Difficulties that consultants experience with implementation may be due to budget restrictions or it may be that clients prefer to use internal resources in this phase. It may also be due to a lack of appreciation for the importance of change management interventions:

Often clients have spent all the money on design and never budget for implementation and even less so for embedding, and so often the benefits of the design are not realized. Organizations seem to run out of steam. They don't realize how important it is to have someone drive the implementation in such a manner as to take it from a paper exercise to workable reality

Clients are keen to design with us, but less enthusiastic about partnering in implementation because 'that's what HR does'. This usually results in [...] disregard

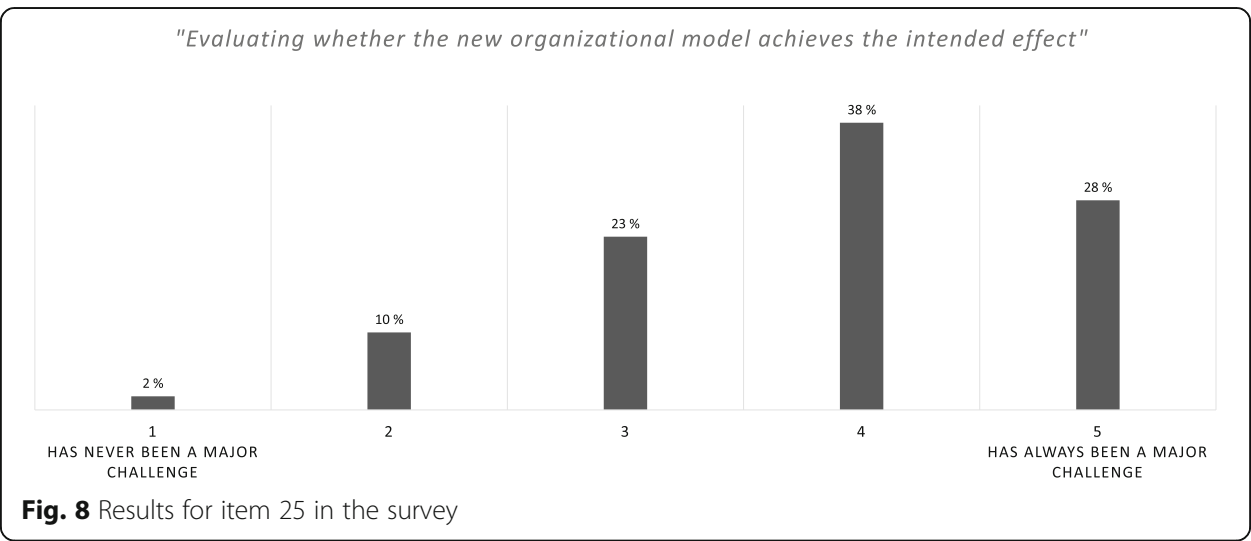




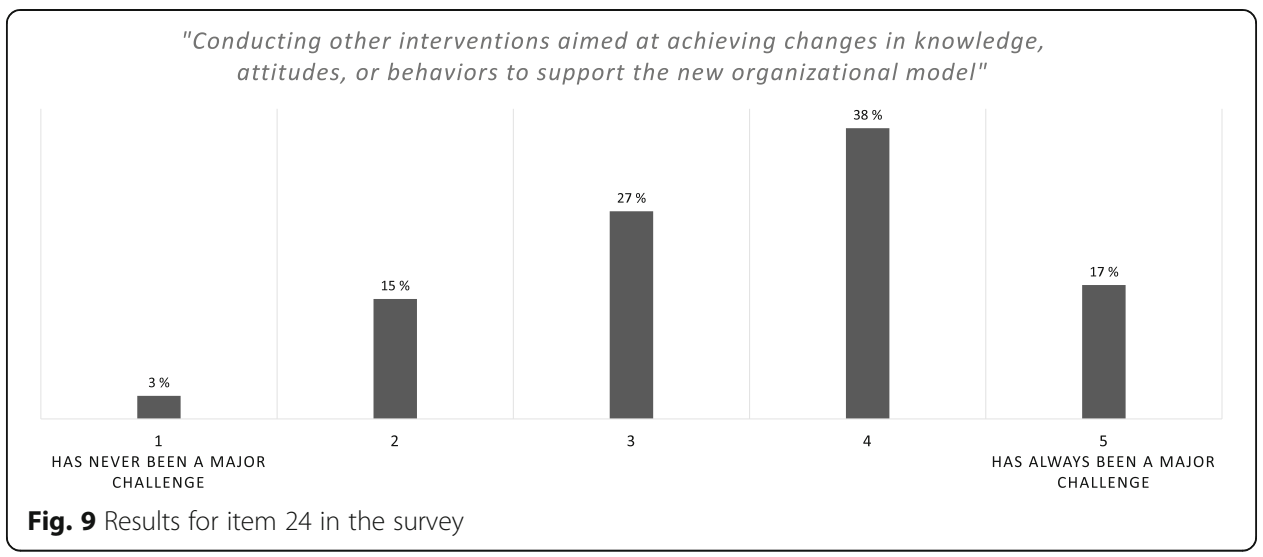

for the elements that make an organization [re-design] successful - KPIs, performance management, culture and behavior change

There are several reasons why evaluation may be a challenge. It may be a practical limitation: Consulting projects are by their very nature of limited duration. As mentioned, implementation may take many months and even years, and the consultants who supported managers in developing the model are not around to observe the effects:

Evaluating the model's impact down the road is usually left in the hands of the [client] organization

Determining whether or not the design has been successful can be difficult (especially in quantitative terms). The implementation work, if done correctly, takes a lot of time $[\ldots]$

There may also be political reasons for avoiding evaluation. Once a decision has been made, the decision maker may not welcome negative news about the limitations of the chosen model (Worren 2018). Another possibility is more psychological, as described by one respondent:

Usually, once "implemented," the energy goes down for evaluating. It's "back to the grind," and the grind is harder now because of the learning curve. Only painful problems tend to gain enough energy to bring corrective adaptations, so positive opportunities are harder to capture

To the extent that the new organization model is evaluated at all, it seems like firms typically focus on the financial benefits (e.g., headcount reductions) and leave out other potential benefits:

In regards to measuring if the new model achieves its intended effect, most of this work is financially driven. There seems to be little appetite to look at "softer" people measures, such as employee engagement, turnover, sick days, etc. 
We also consider the other items in this section-operationalization (Q21), staffing of new roles $(\mathrm{Q} 22)$, and infrastructure $(\mathrm{Q} 23)$ - to be of high importance in terms of implementing a new model and realizing the benefits. The fact that they were evaluated as only moderately challenging may reflect the fact that consultants have developed skills in these areas and have appropriate tools and techniques for the job.

\section{Implications for practitioners}

When considering the first phase of the design process, we found that nearly six out of 10 respondents indicated that it is often or always a challenge to create realistic estimates regarding the time and cost required to complete the project. Our interpretation is that this result partly reflects the unpredictability and complexity of organizational re-designs, but that it also seems to be related to a lack of skills and experience with these kinds of projects. Whatever the cause, one should consider how one can manage the early "contracting phase" more effectively. Consulting firms may offer training in how one best can create common ground with the client about the effort required. With projects of high uncertainty, a "reference class" approach (Flyvbjerg 2008) is sometimes recommended, whereby one consults statistics on several projects completed in the past, instead of deriving time and cost estimates from the activities defined in the project plan for the unique project. However, the difficulty at the present is that such data are lacking, and five out of 10 respondents indicated that it was often or always a challenge to find relevant cases from other comparable organizations.

Secondly, five out of 10 respondents indicated that it is often or always a challenge to understand how people collaborate and/or exchange information across units in the organization. In most cases, the clients have only documented the formal organizational structure, and consultants therefore have to collect information about work processes and informal relations between units in the data gathering phase of the re-design project. The traditional method is to use interviews or workshops. It will probably always be necessary and desirable to conducted interviews and workshops with key stakeholders (both for information gathering, but also for other purposes such as aiding the consultant in interpreting the data and in building support for the project mandate). At the same time, it is also clear from the comments made that many clients have a limited budget and that there are time constraints that may limit the number of interviews and workshops that can be conducted. Hence there may be a need for tools that can help consultants collect and analyze information about how people work, and in particular, the relationships and interdependencies that exist across formal units (for one proposed solution, see Worren et al., 2019).

As for the design phase, the key finding was that more than six out of 10 respondents indicated that it is often or always a challenge to help participants in the process see the larger picture, as opposed to "protecting their own turf." The question is whether this is simply an affirmation of the psychological and political nature of organizational re-design processes, or whether consultants can influence the situation. It is probably dependent on the client or decision maker, and how he/she proceeds in the organization design process. As an extensive literature in management has discussed, there are different ways of leading change processes, and they are not equally effective (ten Have et al., 2018; Appelbaum and Steed 2005). If one has the will, it is possible for leaders to establish psychological safety (Edmondson 1999) and build trust 
among the participants in an organization re-design process. This should in turn reduce the tendency to focus on one's existing role or unit and increase the ability to look at the system as a whole from a strategic point of view. To this end, one may make use of principles and interventions described in the literature on stakeholder management (Freeman 2010), procedural justice or "fair process" (Kim and Mauborgne 1996), action science (Argyris and Schön 1978), high commitment organizations (Beer et al. 2009), idealized design (Ackoff et al. 2006), and "whole systems" approaches (Holman et al. 2007).

With regard to implementation, it was found that six out of 10 respondents indicated that it is often or always a challenge to evaluate whether the organization re-design has achieved the intended effect. It is somewhat paradoxical that firms invest significant amounts of time and money in re-design efforts, without investigating whether the intended benefits are realized. As we mentioned above, there are psychological and political reasons for why decision makers may prefer to avoid an evaluation of outcomes. Yet a lack of evaluation is an obstacle to further learning. It means that one does not receive feedback - at least not based on systematic data-that could have been the basis for improvement in the tools and interventions that are used.

\section{Implications for scholars}

Some of the practitioner challenges identified in our study have been described in the general literature on management and organizations, for example, in the literature on decision-making processes (e.g., Nutt 1999, 2010), client-consultant interaction (e.g., Nikolova and Devinney 2012; Schein 1997), and organizational change (e.g., Beer et al. 2009; Nguyen Huy 2001)

However, there is little exploration of the design process in the organization design literature. Snow (2018) listed all of the articles published in the Journal of Organizatiosn Design since its inception in 2012 until mid-2018. The majority of the articles are theory-driven. He identified only one article (Engler et al. 2013) that was concerned with the design process. It seems obvious to us, however, that the design process should be a key research topic. One opportunity would be more fine-grained, descriptive research. Our study covers the main phases of a re-design project at a fairly high level. This means that we may have ignored some more detailed elements within each phase that may in fact be important for the overall outcome. A second opportunity is to consider the effectiveness of alternative tools and approaches. Organization design is a relatively immature field that is highly dependent on the skills of the individual practitioner. Many alternative tools and methods are in use, and it is unlikely that they are equally effective.

\section{Conclusion}

We have described the results from a survey of 176 organization design consultants. The survey contained 25 items covering the four main phases of the organization design process-from the preparation of the project to implementation of the selected model. The results have implications for both research and practice. First of all, they remind us of the high level of skill that organizational design practitioners need. They need to be able to build trust with the client and other stakeholders, but also challenge 
their thinking and help them imagine alternative realities. They need to master analytical tools and use a fact-based approach, but also understand and manage the emotional reactions to change. They need to be strategic while at the same time consider how concepts and ideas are going to be operationalized and implemented.

For internal and external consultants, the study could be used to structure training programs. We believe that all of the 25 items are potentially important in a re-design process and should be covered in training programs; however, the highest scoring items in this survey may be singled out and receive the most attention as they indicate what the main challenges are. The results also have implications for the development of better tools and techniques. New methods may be needed to aid practitioners in scoping complex projects with high uncertainty and many interrelated elements and for mapping interdependencies and informal relations between units. Finally, the results of this survey should inform academic research. Our study may provide a starting point for business school faculty who want to help build a knowledge base to support evidence-based organization design practice.

\section{Appendix: Methodology ${ }^{2}$}

The initial items were developed by the lead author based on the overall approach for design processes described in Worren (2018) and Nadler and Tushman (1997). The items were then refined after receiving feedback from the other authors. The authors of this article do not necessarily use or recommend the same approach or methodology. This was viewed as an advantage, however, as many different approaches are in use by practitioners (Visscher and Visscher-Voerman 2010). The survey questionnaire would need to be acceptable to consultants with different orientations and preferences with regards to methods. For this reason, the items in the questionnaire do not correspond to any particular framework or methodology. Following the advice of Morrel-Samuels (2002), we created items that asked respondents to estimate a frequency rather than the degree of agreement with a statement. The items listed various challenges, and the respondent was asked to rate the frequency from "1: Is never a challenge" to "5: Is always a challenge". As recommended by Morrel-Samuels (2002) we did not add labels to the items between 1 and 5 (However, when analyzing the results, we interpreted a rating of 4 as "is often a challenge".). Twenty-five items were developed (plus items related to the respondents' background and experience level). The items were grouped into four categories, corresponding to the phases of the typical organization re-design project (as indicated in the main text). It was possible for respondents to add comments after each of the four main sections. Ninety-four comments were added. We read through these comments and have included representative quotes that we believe help in interpreting the results.

Among different practitioners, we believe that management consultants constitute a particularly relevant group. Unlike managers, who only occasionally participate in organizational re-designs, consultants who specialize in this field may participate in one or more projects each year, and thus accumulate extensive experience over time. At the same time, we would expect that their views indirectly reflect managers' (i.e., their clients) concerns and challenges. When commencing this study, we thus concluded that we would contact people who are (or identify themselves) as organization design consultants and

${ }^{2}$ The dataset with the results for all items are available from the Dataverse NO repository (Worren 2019). 
ask them to consider their experience from previous re-design projects. The consultants that we approached were members of the organization design practice in a large, global consulting firm and members of two professional organizations: The Organization Design Forum and the European Organisation Design Forum ${ }^{3}$.

Participants There were 176 participants, divided as follows:

- Consultants in the organization design practice of a global consulting firm (65)

- Members of the European Organisation Design forum (EODF) (45)

- Members of the Organization Design Forum (ODF) (66)

EODF is primarily a European association and ODF is primarily a US association, but both have some members from other countries as well. Among the participants from the consulting firm, around half of the participants (34) came from the US, but there were also participants from Canada, South Africa, Australia and some other countries.

Descriptive data We received 176 usable responses ${ }^{4}$ (the dataset is available from the DataverseNO repository (Worren, 2019)). On average, the respondents had 18 years of work experience and had participated in 15 organization design projects. Of the 109 respondents from ODF and EODF, the majority (60\%) were external consultants, whereas $37 \%$ indicated that they were internal consultants (3\% marked "other").

In one version of the survey (the one for ODF), we also added a question about the typical client of the respondent. A majority (66\%) indicated that the typical client was a large firm, $28 \%$ a medium size firm, and less than 1 percent indicated that a small firm was their typical client. We did not include this item in the survey that was distributed to members of the EODF, but we would expect that the profile would be similar. For the respondents in the global consulting firm, we would similarly expect that the typical client would be a large firm for most of the respondents.

A one-way ANOVA was performed to check whether there were any differences between the three sub-samples. For 19 out of the 25 items, there was no significant difference, whereas there was a significant difference with regards to 6 items. However, the overall pattern that is described below with regards to the findings (i.e., the items rated as the most challenging) was highly similar across the subsamples. For this reason, the three sub-samples have been combined in the subsequent analysis.

Limitations The items asked respondents to make assessments of how frequently they encountered each challenge in their projects. There is a risk that the assessments have been conflated with an assessment of importance (i.e., that unimportant items are rated as less challenging and vice versa). However, this choice was a deliberate one, as we wanted to reduce the number of items in order to increase the response rate. Future research may address this limitation by assessing importance separately from the degree of challenge and by conducting more in-depth

\footnotetext{
${ }^{3}$ The co-authors represent two of the organizations that participated in the research.

${ }^{4}$ Unfortunately, it is not possible to calculate the response rate in the traditional sense. This is due to the fact that in each case, the survey was sent out by the organization in an e-mail message, and it is not known how many people opened the message, and out of those who read the message, how many people considered themselves to be in the target group. However, the representativeness of the results is partly confirmed by the high correlations between the results across the three sub-groups, as mentioned above.
} 
studies of some of the steps in the re-design process. We should also note that the results regarding two of the items in the third section seem to be inconsistent. On the one hand, only 3 out of 10 indicate that it is a challenge to design an organizational model that meets the design criteria (Q20). But at the same time, 6 out of 10 indicate that it is a challenge to avoid the decision maker making a premature commitment (Q13). Normally, we would expect a negative relationship between these two variables: The stronger the tendency to make a premature commitment to a given model, the less likely it should be that one designs a model that meets the design criteria.

\section{Acknowledgements}

We wish the administrators in ODF and EODF, Tanya Spelts and Ana-Maria Cocean, for their help in distributing the survey.

\section{Authors' contributions}

The study was initiated and conducted by NW who also wrote the first draft of the manuscript. JvB and WZ presented the study to their respective communities (EODF and ODF) and planned the distribution and follow-up. JVB and WZ provided feedback on suggested items in the questionnaire and also commented upon the draft version of the manuscript. All authors approved the final manuscript.

\section{Authors' information}

Nicolay Worren is an associate professor at the Norwegian University of Life Sciences. He is the author of "Organization Design: Simplifying complex systems" (Routledge 2018) and writes a blog: www.organizationdesign.net Jeroen van Bree is managing consultant in Berenschot and chair of the European Organisation Design Forum (EODF). $\mathrm{He}$ is also a lecturer at the University of Amsterdam Business School.

William Zybach works as an IT analyst and consultant in US bank and serves as a board member of the Organization Design Forum (ODF).

\section{Funding}

Not applicable.

\section{Availability of data and materials}

The dataset (an SPSS file) used for this study has been archived in the Dataverse NO repository, https://doi.org/10.18710/ WNRIXH.

\section{Competing interests}

The authors declare that they have no competing interests.

\section{Author details}

${ }^{1}$ School of Economics and Business, Norwegian University of Life Sciences (NMBU), P.O. Box 5003, 1432 Aas, Norway. 2European Organisation Design Forum c/o Berenschot Groep B.V., PO Box 8039, 3503, RA, Utrecht, The Netherlands.

${ }^{3}$ Organization Design Forum c/o US Bancorp, 1383 Belmont Drive, Lancaster, VA, USA.

Received: 15 January 2019 Accepted: 1 July 2019

Published online: 25 July 2019

References

Ackoff RL, Magidson J, Addison HJ (2006) Idealized design: creating an organization's future. Wharton School Pub, Upper Saddle River

Appelbaum SH, Steed AJ (2005) The critical success factors in the client-consulting relationship. J Manag Dev 24(1):68-93

Argyris, C., \& Schön, D. A. (1978). Organizational learning (14. print.). Reading Mass.: Addison-Wesley Pub. Co.

Basu S, Savani K (2017) Choosing one at a time? Presenting options simultaneously helps people make more optimal decisions than presenting options sequentially. Organ Behav Hum Decis Processes 139:76-91

Beer M, Eisenstat RA, Foote N (2009) High commitment, high performance: how to build a resilient organization for sustained advantage. Jossey-Bass, San Francisco, Calif

Block, P. (2011). Flawless consulting: a guide to getting your expertise used. Pfeiffer.

Burton RM, Obel B, Døjbak Håkonsson D (2015) Organizational design: a step-by-step approach. Organizational Design: A Step-by-Step Approach, 3rd edn. Cambridge University Press, Cambridge

Edmondson A (1999) Psychological safety and learning behavior in work teams. In: Administrative science quarterly (Vol. 44)

Engler ES, Jones SL, Van de Ven AH (2013) Organizing healthcare for changing markets: the case of ascension health. J Organ Des 2(3):3-15

Flyvbjerg B (2008) Curbing optimism bias and strategic misrepresentation in planning: reference class forecasting in practice. Eur Plan Stud 16(1):3-21

Freeman, R. (2010). Strategic management: a stakeholder approach. Pitman: Boston, MA.

Holman P, Devane T, Cady S (2007) The change handbook: The definitive resource on today's best methods for engaging whole systems. Berrett-Koehler, San Francisco

Huy N (2001) Time, temporal capability, and planned change. Acad Manag Rev 26(4):601-623 
Kim WC, Mauborgne R (1996) Fair process managing in the knowledge economy. Harv Bus Rev 75(4):65-75

Morrel-Samuels P (2002) Getting the truth into workplace surveys. Harv Bus Rev 80(2):111-118

Nadler DA, Tushman ML (1997) Competing by design: the power of organizational architecture. Oxford University Press, New York

Nikolova N, Devinney T (2012) The nature of client-consultant interaction: a critical review. Oxford University Press Nutt PC (1999) Surprising but true: half the decisions in organizations fail. Acad Manag Exec (1993-2005) 13(4):75-90

Nutt PC (2002) Why decisions fail: avoiding the blunders and traps that lead to debacles. Berrett-Koehler Publishers, San Francisco, CA

Nutt PC (2010) Building a decision making action theory. In: Nutt PC, Wilson D (eds) Handbook of Decision Making. John Wiley, Chichester (UK); Hoboken (NJ, pp 155-196

Schein EH (1997) The concept of "client" from a process consultation perspective. J Organ Chang Manag 10(3):202-216

Snow CC (2018) Research in Journal Of Organization Design, 2012-2018. J Organ Des 7(1):1-10

Stanford, N. (2015). Guide to organisation design: creating high-performing and adaptable enterprises. (2nd edition). PublicAffairs.

ten Have S, ten Have W, Huijsmans A-B, Otto M (2018) Reconsidering change management: applying evidence-based insights in change management practice

Visscher K, Visscher-Voerman JIA (2010) Organizational design approaches in management consulting. Manag Decis 48(5):713-731

Werr A, Stjernberg T, Docherty P (1997) The functions of methods of change in management consulting. J Organ Chang Manag 10(4):288-307

Worren N (2019) Organization design: simplifying complex systems, 2nd edn. Routledge, Abingdon, UK

Worren, N. (2019). Organization design practitioner study data set. DataverseNO, https://doi.org/10.18710/WNRIXH.

Worren, N., Christiansen, T., \& Soldal, K. (2019). Using an algorithmic approach for grouping roles and sub-units. Manuscript submitted to Journal of Organization Design, in review.

\section{Publisher's Note}

Springer Nature remains neutral with regard to jurisdictional claims in published maps and institutional affiliations.

\section{Submit your manuscript to a SpringerOpen ${ }^{\circ}$ journal and benefit from:}

- Convenient online submission

- Rigorous peer review

- Open access: articles freely available online

- High visibility within the field

- Retaining the copyright to your article

Submit your next manuscript at $\boldsymbol{\nabla}$ springeropen.com 